\title{
PENERAPAN FUZZY IF-THEN RULES UNTUK PENINGKATAN KONTRAS PADA CITRA HASIL MAMMOGRAFI
}

\author{
Helmy Thendean ${ }^{1}$, Meylina Sugiarto ${ }^{2}$ \\ Program Studi Teknik Informatika, Fakultas Teknologi Informasi, Universitas Tarumanagara \\ Jl. Letjen S. Parman No.1 Jakarta Barat 11440 \\ Telepon: (021)5676260, 5677949 ext.114 \\ E-mail: helmy.fti.untar@gmail.com ${ }^{1}$, helmy@fti.utara.org', Lovelly_bubble@yahoo.com²
}

\begin{abstract}
ABSTRAK: Citra hasil dari mammografi dalam dunia kedokteran sering memiliki kualitas yang buruk dari sisi kontras. Hal ini mengakibatkan kesulitan bagi seorang radiolog untuk menganalisis citra tersebut. Tingkat kesulitan bertambah apabila citra yang harus dianalisis tersebut mengandung kanker atau tumor. Terdapat beberapa metode untuk peningkatan kualitas kontras sebuah citra. Penelitian ini menggunakan metode Fuzzy IF-THEN Rules dengan empat pendekatan basis pengetahuan untuk meningkatkan kualitas kontras citra, khususnya citra payudara yang diperoleh dari hasil mammografi. Untuk menentukan tingkat keberhasilannya, metode tersebut akan dibandingkan dengan metode standar untuk peningkatan kontras seperti Histogram Equalization. Parameter yang digunakan untuk membandingkan setiap metode tersebut adalah linier index of fuzziness dan fuzzy entropy. Hasil percobaan menunjukkan bahwa Fuzzy IF-THEN Rules mampu menghasilkan hasil peningkatan kualitas citra yang lebih baik dibandingkan metode standar. Untuk memperkuat hasil penelitian ini maka dilakukan validasi dengan pakar radiolog dari Rumah Sakit Husada, Jakarta.
\end{abstract}

Kata kunci: fuzzy IF-THEN rules, peningkatan kontras pada citra, histogram equalization, citra kanker payudara hasil mammografi.

\begin{abstract}
In medical area, the quality of an image which is acquired from mammography often has a poor contrast. The poor quality image leads a difficulty for a radiologist to analyze the image. The problem becomes bigger when the image contains a cancer or tumor. There are some methods in image processing technique to increase the contrast quality of an image. This paper presents Fuzzy IF-THEN Rules method which has four knowledge base approaches to increase the contrast quality of the image, especially breast images from mammography. To determine the success rate, this experiment tries to compare this method with a standard contrast improvement such as histogram equalization. The quantity parameters to compare these methods are linier index of fuzziness and fuzzy entropy. The result shows that Fuzzy IF-THEN Rules offers better result to improve the contrast quality than standard method. The result of this experiment is validated by an expert from radiology department from Husada Hospital, Jakarta.
\end{abstract}

Keywords: fuzzy IF-THEN rules, image contrast improvement, histogram equalization, mammography breast cancer images.

\section{PENDAHULUAN}

Dalam bidang kedokteran, radiolog seringkali mengalami kesulitan dalam mengamati citra mentah hasil mammografi karena citra yang dihasilkan mempunyai kualitas buruk, misalnya citra mengalami derau (noise), citra terlalu terang atau gelap, citra kurang tajam, kabur dan sebagainya. Untuk mengatasi hal tersebut perlu dilakukan operasi pengolahan citra. Salah satu operasi pengolahan citra yaitu perbaikan kualitas citra (image enhancement). Perbaikan kualitas citra merupakan proses memperjelas dan mempertajam ciri atau fitur tertentu dari citra agar citra lebih mudah dipersepsi maupun dianalisis secara lebih teliti. Operasi ini bertujuan untuk memperbaiki kualitas citra dengan cara memanipulasi parameter-parameter citra, misalnya untuk perbaikan kontras gelap atau terang.
Peningkatan citra dalam komputasi medis digunakan untuk mengembalikan suatu gambaran yang telah mengalami beberapa macam pembusukan atau untuk meningkatkan corak tertentu dari suatu citra. Citra yang dihasilkan dari peningkatan kontras ini diharapkan dapat lebih memudahkan radiolog untuk mengamati keganjilan di dalam suatu X-ray, CT-Scan, dan lain-lain. Sebagai contoh, radiolog yang sedang meneliti diagnosis jaringan tumor payudara dengan menggunakan digital mammogram perlu untuk mendapatkan hasil yang akurat sehingga sangat dibutuhkan citra yang jelas agar suatu keganjilan mudah untuk diamati. Digital mammogram yang sudah membatasi kontras menyulitkan radiolog untuk mengamati suatu keganjilan. Peningkatan kontras pada citra tersebut dapat membantu radiolog untuk melihat perbedaan struktur dalam citra dan memeriksa 
masing-masing hasil mammografi dengan lebih cepat, sehingga dapat lebih jelas dalam menemukan suatu keganjilan jaringan kanker.

Dalam penelitian ini, dirancang suatu program peningkatan kontras citra. Citra yang dihasilkan dari peningkatan kontras ini diharapkan dapat lebih memudahkan radiolog untuk menganalisis citra hasil mammografi untuk mendeteksi tumor payudara. Metode yang digunakan untuk meningkatkan kontras citra adalah metode Fuzzy IF-THEN rules. Peningkatan kontras citra dengan Fuzzy IF-THEN rules didasarkan pada tingkat keabuan yang memetakan ke dalam suatu fuzzy plane, menggunakan suatu fungsi perubahan bentuk keanggotaan [1]. Tujuannya adalah untuk menghasilkan suatu citra dengan kontras yang lebih tinggi dibanding citra asli yaitu dengan cara memberi suatu berat atau beban lebih besar kepada tingkat keabuan yang semakin dekat dengan rata-rata.

\section{IDENTIFIKASI TUMOR MELALUI CITRA}

Untuk mengetahui kemungkinan terjadinya tumor atau kanker pada tubuh manusia maka perlu dilakukan tes penyaringan kanker. Tes ini dapat mengurangi jumlah kematian akibat kanker, karena jika kanker ditemukan pada stadium paling dini, biasanya dapat diobati sebelum menyebar lebih jauh. Tes penyaringan yang tidak pasti, hasilnya dapat diperkuat atau disangkal oleh pemeriksaan dan tes lanjutan. Salah satu pemeriksaan pembantu untuk menuju diagnosa akhir suatu tumor payudara adalah dengan mammografi, yaitu suatu teknik pemeriksaan foto rontgen untuk jaringan lunak yang memberikan petunjuk adanya kelainan.

Dokter biasanya dapat menentukan jenis tumor dengan melakukan visualisasi dari hasil mammografi kemudian melakukan biopsi dari kanker yang bermetastase dan memeriksanya dengan menggunakan mikroskop namun identifikasi kanker tidak selalu mudah dan pasti. Hal tersebut kadangkala menyulitkan dokter untuk mendiagnosis adanya jaringan tumor tersebut pada tubuh manusia. Operasi perbaikan kualitas citra diperlukan untuk meningkatkan kualitas citra hasil mammografi tersebut. Peningkatan kontras tersebut diharapkan dapat membantu radiolog dalam mendeteksi tumor payudara.

\section{HISTOGRAM CITRA}

Informasi penting mengenai isi citra digital dapat diketahui dengan membuat histogram citra. Histogram citra adalah grafik yang menggambarkan penyebaran kuantitatif nilai derajat keabuan (gray level) piksel di dalam atau bagian tertentu citra [2].
Gambar 1 memperlihatkan contoh sebuah histogram citra, yang dalam hal ini $\mathrm{k}$ menyatakan derajat keabuan dan $n_{k}$ menyatakan jumlah piksel yang memiliki nilai keabuan $\mathrm{k}$.

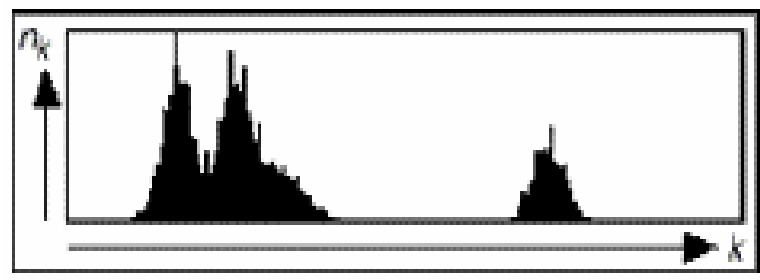

Gambar 1. Histogam Citra [2]

Seringkali pada beberapa operasi pengolahan citra jumlah piksel yang memiliki derajat keabuan $\mathrm{k}$ dinormalkan terhadap jumlah seluruh piksel di dalam citra, sehingga $0 \leq h_{k} \leq 1$.

$$
h_{\mathrm{k}}=\frac{n_{\mathrm{k}}}{n}, \mathrm{k}=0,1, \ldots, \mathrm{L}-1
$$

Keterangan

$\mathrm{k}=$ derajat keabuan

$\mathrm{n}_{\mathrm{k}}=$ jumlah piksel yang memiliki nilai keabuan $\mathrm{k}$.

$\mathrm{n}=$ jumlah total piksel pada citra

Persamaan 1 menyatakan frekuensi kemunculan nisbi (relative) dari derajat keabuan pada citra tersebut. Khusus untuk citra berwarna, histogramnya dibuat untuk setiap kanal RGB (merah, hijau, biru).

Histogram citra menunjukkan banyak hal tentang kecerahan (brightness) dan kontras (contrast) dari sebuah gambar. Puncak histogram menunjukkan intensitas piksel yang menonjol. Lebar dari puncak menunjukkan rentang kontras dari gambar. Citra yang mempunyai kontras terlalu cerah atau terlalu gelap memiliki histogram yang sempit. Histogamnya terlihat hanya menggunakan setengah dari daerah derajat keabuan. Citra yang baik memiliki histogram yang mengisi daerah derajat keabuan secara penuh dengan distribusi yang merata pada setiap derajat keabuan piksel. Semakin ke kiri grafik pada histogram menandakan citra semakin gelap. Sebaliknya, semakin ke kanan grafik pada histogram menandakan citra semakin cerah. Jika grafik berada di tengah-tengah berarti citra tersebut cukup tingkat kecerahannya. Histogram pada citra yang gelap menunjukkan bahwa gray level terkonsentrasi di bagian kiri atau bagian gelap dari range gray scale. Sebaliknya pada citra cerah, gray level terkonsentrasi di bagian kanan atau bagian cerah dari range gray scale. Pada citra berkontras rendah, histogram memiliki bentuk yang sempit yang menunjukkan bahwa citra memiliki dynamic range rendah. Sedangkan pada citra berkontras tinggi, gray level tersebar luas. Gambar 2 menunjukkan histogram dan contoh citra gray scale dari empat jenis citra secara umum. 


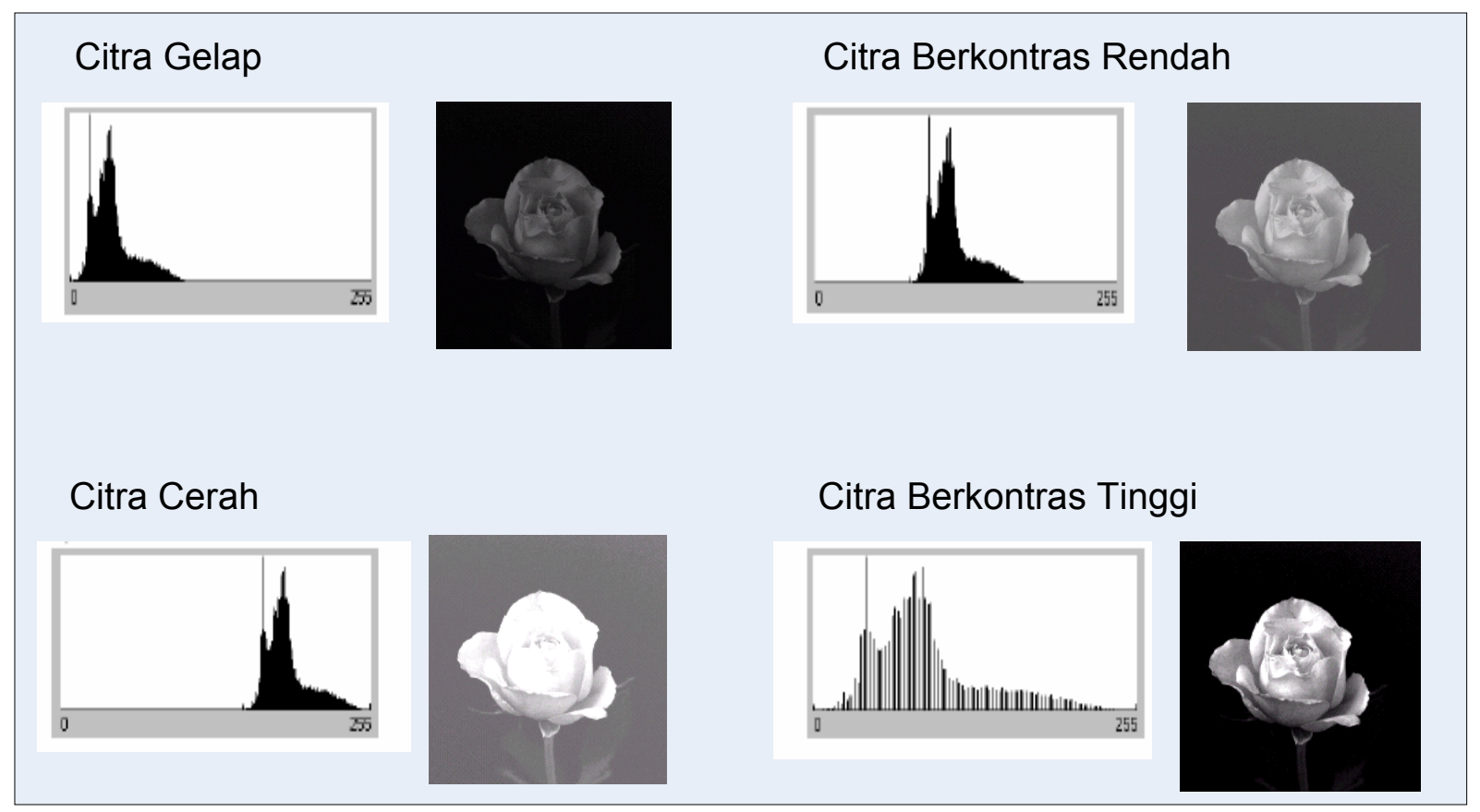

\section{Gambar 2. Jenis-jenis Dasar Histogram dan Contoh Citra Gray Scale [3]}

Citra yang kontras adalah citra yang memiliki perbedaan intensitas warna piksel yang tinggi antara warna piksel satu dengan piksel yang lain, sehingga citra dapat terlihat jelas [4]. Citra yang kontras pada grafik histogram akan terlihat menyebar. Citra yang kontras akan memiliki frekuensi intensitas warna pada piksel tersebar mulai dari intensitas warna piksel 0 hingga intensitas warna piksel 255 , sehingga grafik histogram pada citra kontras akan terlihat menyebar. Sedangkan citra yang kurang kontras adalah citra yang memiliki perbedaan intensitas warna piksel yang rendah antara warna piksel yang satu dengan piksel yang lain, sehingga citra terlihat kurang jelas [4]. Citra yang memiliki kontras rendah dapat terjadi karena kurangnya pencahayaan, kurangnya bidang dinamika dari sensor citra, atau kesalahan setting pembuka lensa pada saat pengambilan citra.

\section{FUZZY IMAGE PROCESSING}

Fuzzy Image Processing adalah koleksi dari semua pendekatan yang memahami, menghadirkan dan memproses citra, corak dan segmen sebagai penetapan fuzzy. Penyajian dan proses tergantung pada teknik pemilihan fuzzy dan masalah untuk dipecahkan [1]. Fuzzy Image Processing mempunyai tiga tahap utama: image fuzzification, modifikasi nilainilai keanggotaan, dan image defuzzification seperti yang ditunjukkan pada Gambar 3.

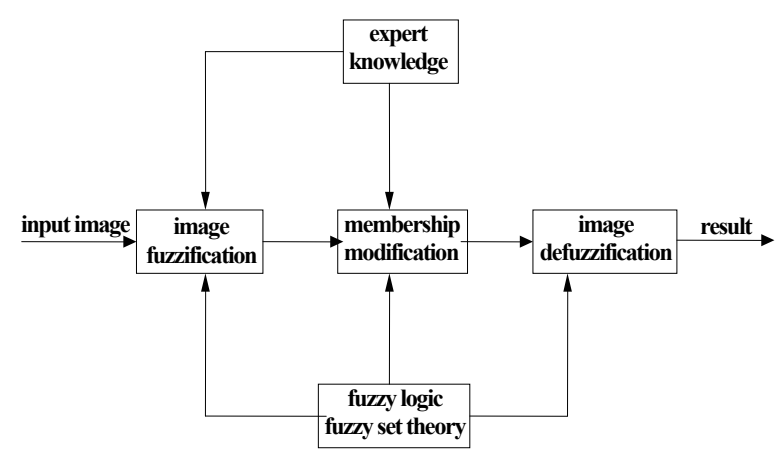

Gambar 3. Tahap-tahap Fuzzy Image Processing [1]

Secara umum algoritma Fuzzy Image Processing terdiri dari tahapan-tahapan sebagai berikut:

1. Tampilkan citra yang akan diproses.

2. Lakukan proses fuzzifikasi, yaitu menentukan derajat dari setiap input pada himpunan fuzzy yang sesuai.

3. Modifikasi nilai keanggotaan dengan menggunakan aturan yang sesuai.

4. Lakukan proses defuzzifikasi, yaitu mengubah besaran fuzzy yang disajikan dalam bentuk himpunan fuzzy keluaran dengan fungsi keanggotaannya untuk mendapatkan kembali bentuk tegasnya. Selanjutnya, fuzzy output akan dimasukkan pada proses defuzzifikasi untuk menghasilkan crisp output. Hasil output berupa nilai gray level baru. 


\section{FUZZY IF-THEN RULES}

Proses logika fuzzy terdiri dari 3 proses yaitu fuzzifikasi (fuzzification), modifikasi nilai keanggotaan (membership modification) dan defuzzifikasi (defuzzification). Block diagram Fuzzy IF-THEN Rules dapat dilihat pada Gambar 4.

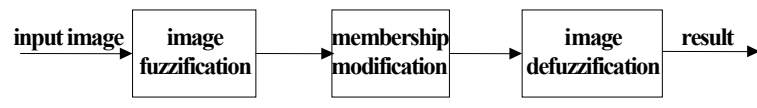

\section{Gambar 4. Block Diagram Fuzzy IF-THEN Rules}

Langkah-langkah peningkatan kontras citra dengan menggunakan metode Fuzzy IF-THEN Rules adalah [5]:

1. Masukkan citra yang akan diproses

2. Pengaturan parameter yaitu:

a. Input corak dan fungsi keanggotaan. Sebuah crisp input yaitu nilai gray level digunakan sebagai input pada proses fuzzifikasi untuk menghasilkan fuzzy input sesuai dengan membership function input yang dibuat.

b. Tentukan nilai gray level minimum dan maksimum.

c. Hitung nilai gray level medium

$\mathrm{G}_{\text {mid }}=(\max +\min ) / 2$

3. Lakukan proses fuzzifikasi, yaitu proses perubahan masukan variabel fuzzy menjadi peubah fuzzy yang disajikan dalam bentuk himpunan-himpunan fuzzy dengan suatu fungsi keanggotaannya masingmasing. Oleh sebab itu langkah pertama yang harus dilakukan adalah mendesain himpunanhimpunan fuzzy yang disajikan dalam bentuk fungsi keanggotaan. Fungsi keanggotaan diwakili dengan dark, gray, dan bright, dalam satuan piksel.

4. Modifikasi nilai keanggotaan dengan menggunakan tiga aturan yaitu:

if dark then black

if gray then gray

if bright then white

Nilai-nilai fuzzification dark, gray, dan bright dapat ditentukan dari titik saat mendesain fungsi keanggotaan.

5. Lakukan proses defuzzifikasi, yaitu mengubah besaran fuzzy yang disajikan dalam bentuk himpunan fuzzy keluaran dengan fungsi keanggotaannya untuk mendapatkan kembali bentuk tegasnya. Selanjutnya, fuzzy output akan dimasukkan pada proses defuzzifikasi untuk menghasikan crisp output.

Tahapan yang diperlukan dalam proses fuzzifikasi dan defuzzifikasi adalah sebagai berikut [6]:
1. Fuzzifikasi

Pada tahap ini rule yang ada akan ditinjau kembali dan menentukan crisp input $\mathrm{x} 1$ dan $\mathrm{y} 1$, kemudian menentukan derajat atau tingkat kepercayaan dari setiap input pada himpunan fuzzy yang sesuai. Crisp input selalu mempunyai nilai kuantitatif yang dibatasi oleh himpunan semesta.

2. Rule evaluation

Evaluasi aturan merupakan proses pengambilan keputusan (inference) yang berdasarkan aturanaturan yang ditetapkan pada basis aturan (rules base) untuk menghubungkan antar peubah-peubah fuzzy masukan dan peubah fuzzy keluaran. Aturanaturan ini berbentuk jika ... maka (IF ... THEN). Pada tahap ini, hasil dari fuzzifikasi pada setiap rule akan dilihat kembali. Apabila pada rule ditemukan 'AND' maka akan dicari nilai minimumnya, sedangkan jika ditemukan 'OR' maka akan dicari nilai maksimumnya.

$\mu_{\text {aub }}(\mathrm{x})=\max \left[\mu_{\mathrm{A}}(\mathrm{x}), \mu_{\mathrm{B}}(\mathrm{x})\right]$

atau

$\mu_{\mathrm{anb}}(\mathrm{x})=\min \left[\mu_{\mathrm{A}}(\mathrm{x}), \mu_{\mathrm{B}}(\mathrm{x})\right]$

3. Defuzzifikasi

Defuzzifikasi merupakan cara untuk merubah suatu fuzzy set yang diperoleh dari hasil komposisi beberapa rule, menjadi suatu bilangan yang merupakan dominan fuzzy set tersebut. Defuzzifikasi yang dipakai adalah Sugeno. Weight Average Defuzzifier digunakan untuk penalaran fuzzy metode Sugeno.

Bentuk umum fuzzy metode Sugeno Orde-Nol adalah:

IF $\left(x_{i}\right.$ is $\left.A_{i}\right) \ldots\left(x_{n}\right.$ is $\left.A_{n}\right)$ THEN $z=k$ dengan $\mathrm{Ai}$ adalah himpunan fuzzy ke-i dan $\mathrm{k}$ adalah konstanta.

Persamaan umum fuzzy metode Sugeno:

$$
I=\frac{\sum_{i=1}\left(\alpha_{i} x N K_{i}\right)}{\sum_{i=1} \alpha_{i}}
$$

Keterangan:

$\alpha_{\mathrm{i}}$ : nilai keanggotaan fuzzy pada LHS (left hand side) IF-THEN Rule

$\mathrm{NK}_{\mathrm{i}}$ : nilai konsekuen / konstanta pada IF-THEN Rule

\section{LINEAR INDEX OF FUZZINESS DAN FUZZY ENTROPY}

Peningkatan atau pengurangan kekaburan citra dapat digunakan dalam pemrosesan citra seperti perbaikan citra, penggolongan dan segmentasi citra. Arnold Kaufmann memperkenalkan linear index of fuzziness sebagai berikut [1]: 


$$
\gamma_{1}=\frac{2}{M N} \sum_{m} \sum_{n} \min \left(\mu_{m n}, 1-\mu_{m n}\right)
$$

di mana suatu citra dengan ukuran $\mathrm{MxN}$, dan mengkalkulasi kekaburan pada perbedaan antara nilai keanggotaan dan komplemennya. Indeks kuadrat dari kekaburan dapat digambarkan dengan cara yang serupa yaitu:

$$
\gamma_{q}=\frac{2}{\sqrt{M N}}\left[\sum_{m} \sum_{n}\left\{\min \left(\mu_{m n}, 1-\mu_{m n}\right)\right\}^{2}\right]^{\frac{1}{2}}
$$

Jumlah kekaburan adalah nol jika semua keanggotaan adalah 0 atau 1, (contoh: citra biner). Kekaburan mencapai maksimum jika semua keanggotaan sama dengan 0.5 .

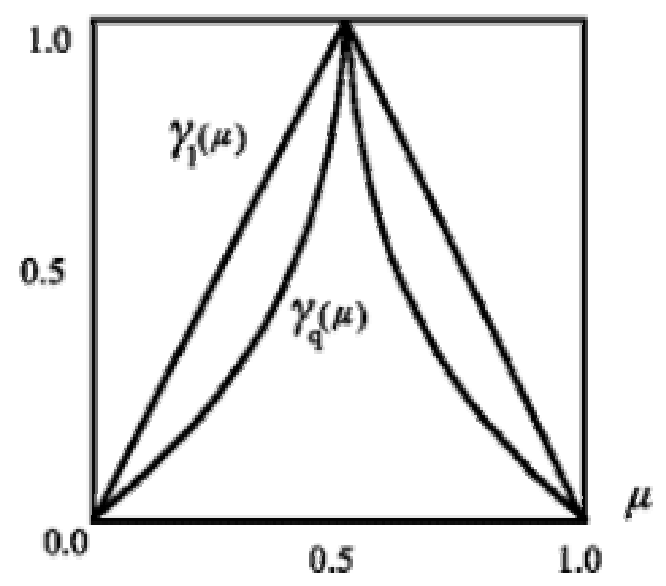

Gambar 5. Fungsi Linear Index of Fuzziness dan Fuzzy Entropy [1]

Selain itu, ada cara-cara lain untuk mengkalkulasi kekaburan citra. Deluca dan Termin memperkenalkan fuzzy entropy yaitu:

$$
\begin{aligned}
& H_{\log }(x)=\frac{1}{M N \ln 2} \sum_{m} \sum_{n} S_{n}\left(\mu_{m n}\right) \\
& S_{n}\left(\mu_{m n}\right)=-\mu_{m n} \ln \mu_{m n}-\left(1-\mu_{m n}\right) \ln \left(1-\mu_{m n}\right)
\end{aligned}
$$

Dalam penelitian ini, setiap pendekatan basis pengetahuan dengan metode Fuzzy IF-THEN Rules dihitung nilai linear index of fuzziness dan nilai fuzzy entropy masing-masing. Semakin kecil nilai linear index of fuzziness dan nilai fuzzy entropy yang diperoleh maka semakin baik kualitas dari metode yang digunakan.

\section{OBYEK PENELITIAN}

Dalam penelitian ini, data yang digunakan adalah citra gray scale hasil mammografi yang diperoleh dari Rumah Sakit Husada Jakarta. Citra tersebut merupakan contoh sampel data hasil mamografi milik pasien yang berusia di atas 30 tahun. Jumlah citra yang akan digunakan untuk percobaan adalah 50 buah. Citra tersebut memiliki resolusi 24 bit dengan ukuran maksimal 1024 x 1024 piksel. Contoh citra yang digunakan dalam penelitian ini dapat dilihat pada Gambar 6.

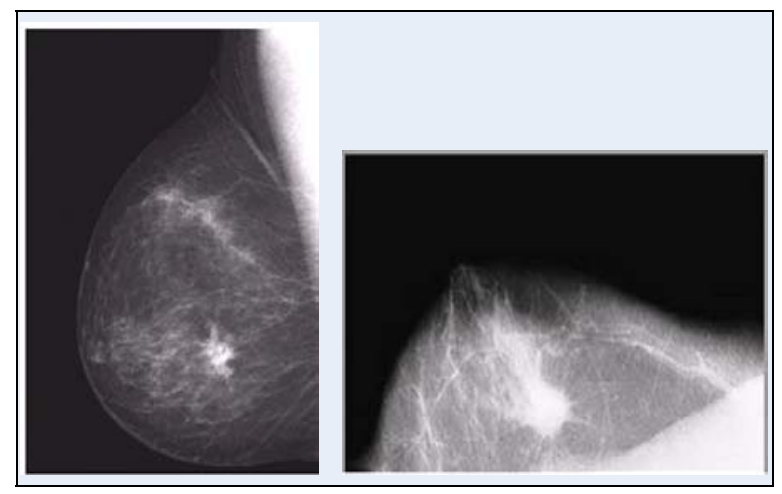

Gambar 6. Contoh Citra Hasil Mammografi

\section{IMPLEMENTASI}

Langkah-langkah untuk proses peningkatan kontras citra dengan metode Fuzzy IF-THEN Rules adalah [5]:

1. Tampilkan citra gray scale yang akan diproses.

2. Pengaturan parameter

a. Input corak dan fungsi keanggotaan.

b. Menetapkan nilai gray level minimum dan nilai gray level maksimum.

c. Hitung nilai gray level $\mathrm{mid}=(\max +\min ) / 2$

3. Lakukan proses fuzzifikasi yaitu proses perubahan masukan variabel fuzzy menjadi peubah fuzzy yang disajikan dalam bentuk himpunan-himpunan fuzzy dengan suatu fungsi keanggotaannya masingmasing. Karena itu, langkah pertama yang harus dilakukan adalah mendesain himpunan-himpunan fuzzy yang disajikan dalam bentuk fungsi keanggotaan. Fungsi keanggotaan diwakili dengan dark, gray, dan bright, dalam satuan pixel. Desain fungsi keanggotaan fuzzy IF-THEN rules dalam penelitian ini dibagi menjadi empat pendekatan yang dapat dilihat pada Gambar 7 sampai dengan Gambar 10. 


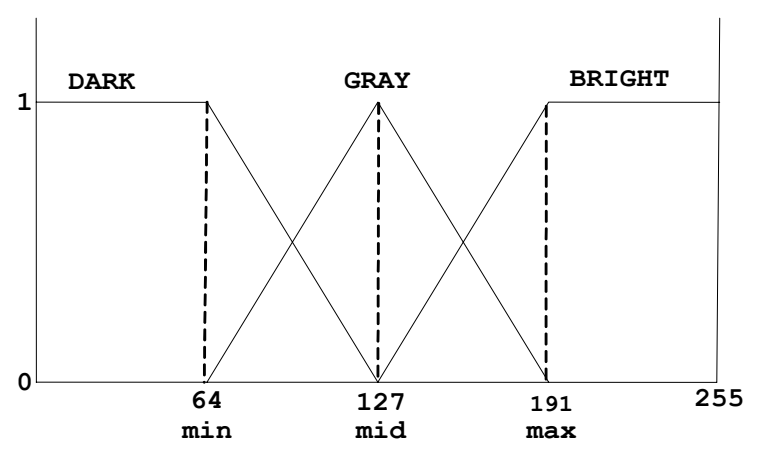

Gambar 7. Desain fungsi keanggotaan Fuzzy IFTHEN Rules dengan Pendekatan 1

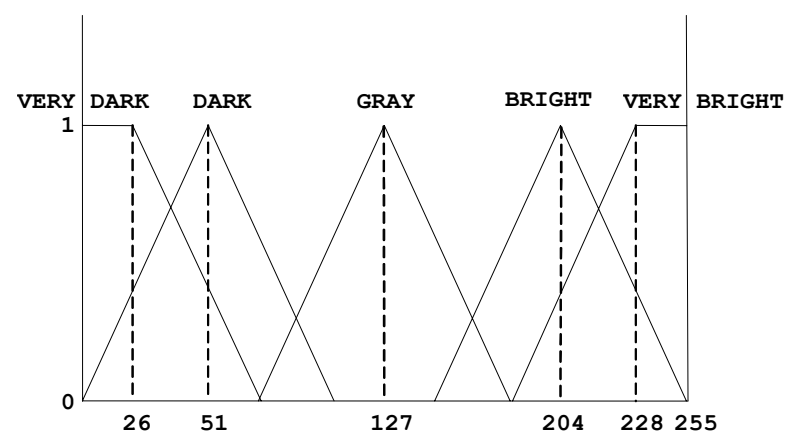

Gambar 8. Desain fungsi keanggotaan Fuzzy IFTHEN Rules dengan Pendekatan 2

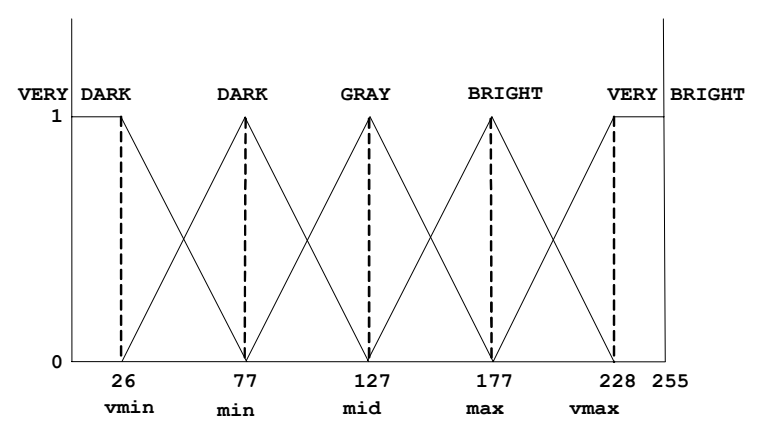

Gambar 9. Desain fungsi keanggotaan Fuzzy IFTHEN Rules dengan Pendekatan 3

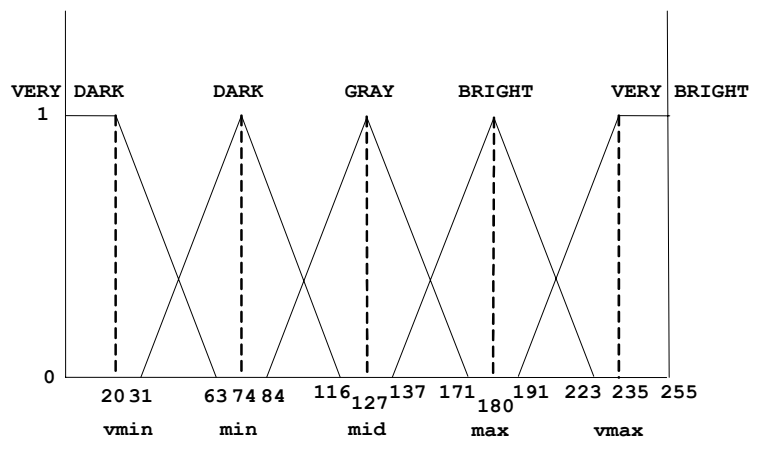

Gambar 10. Desain fungsi keanggotaan Fuzzy IFTHEN Rules dengan Pendekatan 4
4. Modifikasi nilai keanggotaan, di sini diperlihatkan contoh dengan menggunakan pendekatan 3 (lima aturan):

IF very dark THEN 26

IFdark THEN 77

IF gray THEN 127

IF bright THEN 177

IF very bright THEN 228

Nilai-nilai fuzzifikasi very dark, dark, gray, bright, dan very bright dapat ditentukan dari titik saat mendesain fungsi keanggotaan. Nilai dark, gray dan bright sudah dapat ditentukan dari titik saat mendesain fungsi keanggotaan.

Nilai gray $=$ nilai gray level $255 \times 1 / 2=127$.

Nilai dark $=$ nilai gray level $127-50=77$.

Nilai very dark $=$ nilai gray level $77-51=26$.

Nilai bright $=$ nilai gray level $127+50=177$.

Nilai very bright $=$ nilai gray level $177+$ nilai 51 yaitu 228.

Penentuan nilai-nilai tersebut berdasarkan pendekatan perubahan intensitas pixel pada setiap nilai linguistik sebesar \pm 50 pixel.

5. Lakukan proses defuzzifikasi yaitu mengubah besaran fuzzy yang disajikan dalam bentuk himpunan fuzzy keluaran dengan fungsi keanggotaannya untuk mendapatkan kembali bentuk tegasnya. Selanjutnya, fuzzy output akan dimasukkan pada proses defuzzifikasi untuk menghasikan crisp output. Hasil output dari defuzzifikasi ditentukan dengan menggunakan nilai gray level vminimum $\left(\mathrm{g}_{\mathrm{vmin}}\right)$, minimum $\left(\mathrm{g}_{\text {min }}\right)$, medium $\left(\mathrm{g}_{\text {mid }}\right)$, maksimum $\left(\mathrm{g}_{\max }\right)$, dan vmaksimum $\left(\mathrm{g}_{\mathrm{vmax}}\right)$. Gray level yang baru dihitung dengan rumus berdasarkan persamaan 6 menjadi:

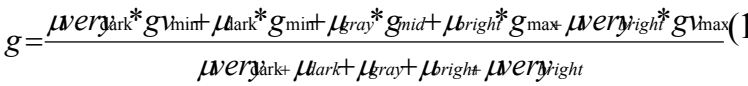

Pengujian pada data dilakukan untuk memperoleh hasil perhitungan nilai linear index of fuzziness dan nilai fuzzy entropy yang dihasilkan dari program untuk setiap pendekatan. Hasil perhitungan berupa rata-rata nilai index of fuzziness dan nilai fuzzy entropy dari setiap pendekatan yang dilakukan dapat dilihat pada Tabel 1.

Untuk memvalidasi hasil pengujian maka citra hasil proses dari keempat pendekatan sebelumnya diperlihatkan kepada radiolog untuk menentukan mana pendekatan yang terbaiknya dari sudut pandangnya. Pengujian dengan radiolog tersebut dilakukan dengan menambahkan juga citra hasil metode peningkatan kontras standar (histogram equalization). Hasil pengujian menunjukkan bahwa dari 50 citra yang diberikan, radiolog memilih 48 citra hasil pendekatan 3 sebagai yang terbaik. Hanya 2 citra yang berasal dari pendekatan 4 yang dipilih oleh radiolog sebagai yang terbaik.. 
Tabel 1. Hasil Perhitungan Rata-rata Nilai Index of Fuzziness dan Fuzzy Entropy

\begin{tabular}{lcc}
\hline & $\begin{array}{c}\text { Rata-rata Nilai } \\
\text { Index of Fuzziness }\end{array}$ & $\begin{array}{c}\text { Rata-rata Nilai } \\
\text { Fuzzy Entropy }\end{array}$ \\
\hline $\begin{array}{l}\text { Metode Fuzzy IF-THEN } \\
\text { Rules Pendekatan 1 }\end{array}$ & 0.1258 & 0.0938 \\
$\begin{array}{l}\text { Metode Fuzzy IF-THEN } \\
\text { Rules Pendekatan 2 }\end{array}$ & 0.1107 & 0.0852 \\
$\begin{array}{l}\text { Metode Fuzzy IF-THEN } \\
\text { Rules Pendekatan 3 }\end{array}$ & 0.1107 & 0.0852 \\
$\begin{array}{l}\text { Metode Fuzzy IF-THEN } \\
\text { Rules Pendekatan 4 }\end{array}$ & 0.0964 & 0.0673 \\
\hline
\end{tabular}
yaitu:

Selama proses pengujian ditemukan beberapa hal

1. Program Peningkatan Kontras Citra dengan Metode Fuzzy IF-THEN Rules dengan pendekatan 1 menghasilkan citra dengan kualitas yang lebih gelap dibandingkan citra asli sebelum diproses.

2. Program Peningkatan Kontras Citra dengan Metode Fuzzy IF-THEN Rules dengan pendekatan 2 menghasilkan citra dengan kualitas yang lebih terang namun ada bagian tertentu yang mengandung jaringan payudara cenderung menghilang.

3. Program peningkatan kontras dengan metode Histogram Equalization menghasilkan kualitas citra yang terlalu terang atau cenderung kabur sehingga citra tersebut menjadi kurang jelas untuk dianalisis.

\section{KESIMPULAN DAN SARAN}

Dari hasil penelitian ini dapat ditarik kesimpulan sebagai berikut:

1. Peningkatan kontras citra dengan metode Fuzzy IF-THEN Rules dapat dikatakan berhasil, terbukti dari hasil percobaan dapat dilihat radiolog lebih memilih citra hasil proses dengan Fuzzy IF-THEN Rules dibanding citra aslinya.

2. Semakin kecil nilai linear index of fuzziness dan nilai fuzzy entropy yang dihasilkan dari proses peningkatan kontras citra tidak selalu menghasilkan citra dengan kualitas paling baik menurut radiolog, karena berdasarkan hasil pengujian dapat dilihat bahwa hasil kualitas citra yang paling baik dari proses peningkatan kontras citra yang diperoleh dari perhitungan nilai linear index of fuzziness dan nilai fuzzy entropy tidak selalu sama dengan hasil kualitas citra yang paling baik menurut pengamatan radiolog.

3. Hasil proses peningkatan kontras citra dengan metode Histogram Equalization memiliki kualitas citra lebih buruk dibandingkan dengan metode Fuzzy IF-THEN Rules karena citra yang dihasilkan dari metode Histogram Equalization terlalu terang sehingga menyulitkan radiolog untuk menganalisis citra tersebut.

Beberapa saran agar dapat dilanjutkan untuk pengembangan berikut, antara lain:

1. Bagi peneliti lain yang ingin melakukan penelitian mengenai peningkatan kontras citra, ada baiknya penelitian ini dikembangkan misalnya dengan melakukan perbandingan dengan metode-metode peningkatan kontras citra yang lain sehingga dapat diketahui hasil peningkatan kontras citra dengan metode mana yang lebih baik kualitasnya.

2. Dapat diteliti bagaimana hasilnya jika hasil dari peningkatan kontras dengan metode yang digunakan dalam penelitian ini digunakan untuk pendeteksian tumor payudara.

\section{DAFTAR PUSTAKA}

1. Tizhoosh, Fuzzy Image Processing, http://pami. uwaterloo.ca/tizhoosh/fip.htm, akses Desember 2006.

2. Munir, Rinaldi, Aplikasi Image Thresholding untuk Segmentasi Objek, http://www.informatika. org/ rinaldi/Citra/Tugas1.pdf, akses Desember 2006.

3. Nugroho, Setyo, Implementasi Metode Contrast Stretching untuk Memperbaiki Kontras Citra, http://sn.visiglobal.net/pub/RR-01-2005-TIKOM. pdf, akses Desember 2006.

4. Gonzales, Rafael C., Digital Image Processing. Addison-Wesley Publishing Company, 2002.

5. Hassanien, Aboul Ella., and Amr Badr, A Comparative Study on Digital Mamography Enhancement Algorithms Based on Fuzzy Theory, Journal of Studies in Informatics and Control, Vol. 12 part 1, 2003.

6. Negnevitsky, Michael, Artificial Intelligence: A Guide to Intelligent System, Boston: PWS-KENT, 2002. 